Published in final edited form as:

J Consult Clin Psychol. 2012 April ; 80(2): 186-195. doi:10.1037/a0026700.

\title{
Racial/Ethnic Differences in Adults in Randomized Clinical Trials of Binge Eating Disorder
}

\author{
Debra L. Franko, \\ Department of Counseling and Applied Educational Psychology, Northeastern University \\ Heather Thompson-Brenner, \\ Department of Psychology, Boston University
}

Douglas R. Thompson,

Thompson Research Consulting LLC, Milwaukee, Wisconsin

Christina L. Boisseau,

Department of Psychology, Boston University

Angela Davis,

Department of Psychology, Boston University

Kelsie T. Forbush,

Department of Psychology, Purdue University

James P. Roehrig,

Department of Counseling and Applied Educational Psychology, Northeastern University

Susan W. Bryson,

Department of Medicine, Stanford University School of Medicine

Cynthia M. Bulik,

Department of Psychiatry, University of North Carolina at Chapel Hill

Scott J. Crow,

Department of Psychiatry, University of Minnesota Medical School

Michael J. Devlin,

Department of Psychiatry, Columbia University College of Physicians and Surgeons

Amy A. Gorin,

Department of Psychology, University of Connecticut

Carlos M. Grilo,

Department of Psychiatry, Yale University School of Medicine

Jean L. Kristeller,

Department of Psychology, Indiana State University

Robin M. Masheb,

Department of Psychiatry, Yale University School of Medicine

James E. Mitchell,

\footnotetext{
(C) 2011 American Psychological Association

Correspondence concerning this article should be addressed to Debra L. Franko, Department of Counseling and Applied Educational Psychology, 404 INV, Northeastern University, Boston, MA 02115. d.franko@neu.edu.

Portions of this article were presented at the 16th Annual Meeting of the Eating Disorders Research Society, Boston, October 2010.
} 
Department of Clinical Neuroscience, University of North Dakota School of Medicine and Health Sciences

Carol B. Peterson, Department of Psychiatry, University of Minnesota Medical School

Debra L. Safer, Department of Psychiatry and Behavioral Sciences, Stanford University School of Medicine

Ruth H. Striegel, Department of Psychology, Wesleyan University

Denise E. Wilfley, and

Department of Psychiatry, Washington University School of Medicine in St. Louis

G. Terence Wilson

Department of Psychology, Rutgers, The State University of New Jersey

\section{Abstract}

Objective-Recent studies suggest that binge eating disorder (BED) is as prevalent among African American and Hispanic Americans as among Caucasian Americans; however, data regarding the characteristics of treatment-seeking individuals from racial and ethnic minority groups are scarce. The purpose of this study was to investigate racial/ethnic differences in demographic characteristics and eating disorder symptoms in participants enrolled in treatment trials for BED.

Method-Data from 11 completed randomized, controlled trials were aggregated in a single database, the Clinical Trials of Binge Eating Disorder (CT-BED) database, which included 1,204 Caucasian, 120 African American, and 64 Hispanic participants assessed at baseline. Age, gender, race/ethnicity, education, body mass index (BMI), binge eating frequency, and Eating Disorder Examination (EDE) Restraint, Shape, Weight, and Eating Concern subscale scores were examined.

Results-Mixed model analyses indicated that African American participants in BED treatment trials had higher mean BMI than Caucasian participants, and Hispanic participants had significantly greater EDE shape, weight, and eating concerns than Caucasian participants. No racial or ethnic group differences were found on the frequency of binge eating episodes. Observed racial/ethnic differences in BED symptoms were not substantially reduced after adjusting for BMI and education. Comparisons between the CT-BED database and epidemiological data suggest limitations to the generalizability of data from treatment-seeking samples to the BED community population, particularly regarding the population with lower levels of education.

Conclusions-Further research is needed to assess alternative demographic, psychological, and culturally specific variables to better understand the diversity of treatment-seeking individuals with BED.

\section{Keywords}

binge eating; eating disorders; treatment; health disparities; ethnicity

Binge eating disorder (BED) is the most prevalent eating disorder diagnosis and is observed across racial and ethnic groups (Hudson, Hiripi, Pope, \& Kessler, 2007; Striegel-Moore \& Franko, 2008). BED is characterized by regular consumption of objectively large amounts of food accompanied by a subjective sense of loss of control over eating, and is associated with heightened psychiatric and medical comorbidities and symptoms (Dickerson et al., 2011; Grilo, 2003; Wonderlich, Gordon, Mitchell, Crosby, \& Engel, 2009). 
Obesity is a risk associated with BED and may also be the result of persistent binge eating (Grilo, 2003; Marcus \& Wildes, 2009; Striegel-Moore \& Franko, 2008). Epidemiological studies indicate that obesity is significantly more common in minority women than in Caucasian women and is disproportionately rising among African Americans and Hispanics (Flegal, Carroll, Ogden, \& Curtin, 2010). The prevalence of binge eating has been estimated to be as high as $21 \%-48 \%$ among overweight and obese individuals in racially/ethnically diverse populations (Latner, Wetzler, Goodman, \& Glinski, 2004), yet the relationships among body mass index (BMI), BED symptoms, and sociocultural and psychological factors in racial/ethnic minority samples have not been investigated.

To date, studies of race/ethnicity in BED have been largely limited to epidemiologic or community samples (Marques et al., 2011). Community-based studies have reported significant racial/ethnic differences in the clinical presentations of Black and White women with BED (Pike, Dohm, Striegel-Moore, Wilfley, \& Fairburn, 2001; Striegel-Moore et al., 2005). Little is known about racial/ethnic differences among treatment seekers with BED because treatment studies typically have insufficient racial/ethnic minority representation to allow statistical comparisons. Moreover, the few available studies of racial/ethnic differences in BED noted that a sampling bias appears to exist between White and Black treatment-seeking and community women with BED (Grilo, Lozano, \& Masheb, 2005; Wilfley, Pike, Dohm, Striegel-Moore, \& Fairburn, 2001). African American women with BED in a clinical sample were older, had higher BMIs, and had more eating disorder symptoms than African American women with BED drawn from a community sample from the same geographic region (Grilo, Lozano, \& Masheb, 2005). Further research comparing treatment-seeking individuals with BED to epidemiological data is needed to help identify the characteristics of those who seek treatment (within and across racial and ethnic groups) and to assess the generalizability of BED treatment study samples to the general population.

It is particularly important to consider the possible role of socioeconomic status (SES) in observed racial/ethnic health disparities in those seeking treatment. Authors have argued that relationships between SES and health variables may be conditional or interactional and that race and class should be examined as both main effects and interactions (Farmer \& Ferraro, 2005). Although lower SES has been observed as a risk factor for BED across racial/ethnic groups, studies of symptom patterns among those with BED have rarely included questions related to SES (Marcus, Bromberger, Wei, Brown, \& Kravitz, 2007).

The objective of this study was to compare demographic variables and baseline symptomatology of treatment-seeking African Americans and Hispanics with those of Caucasians enrolled in treatment trials of BED. Additional exploratory analyses compared demographic variables and BMI between these treatment-seeking samples and publicly available community survey data.

\section{Method}

\section{Participants}

Deidentified data were aggregated (Clinical Trials of Binge Eating Disorder [CT-BED] database) from 11 treatment trials for BED conducted in the United States since 1995 (Devlin et al., 2005; Gorin, Le Grange, \& Stone, 2003; Grilo \& Masheb, 2005; Grilo, Masheb, \& Salant, 2005; Grilo, Masheb, \& Wilson, 2005; Kristeller, 2007; Peterson, Mitchell, Crow, Crosby, \& Wonderlich, 2009; Safer, Robinson, \& Jo, 2010; Shapiro et al., 2007; Wilfley et al., 2002; Wilson, Wilfley, Agras, \& Bryson, 2010). Treatment studies were selected based on the criteria that the study (a) was a randomized, controlled trial (RCT); (b) included at least 10 participants; (c) was either published in a peer-reviewed journal or funded through a peer-reviewed process; and (d) was conducted in the United 
States. After description of the study, written informed consent was obtained. The current analyses of baseline data included all participants in the studies from Caucasian $(n=1,204)$, African American $(n=120)$, and Hispanic $(n=64)$ racial/ethnic groups. The human subjects review committees of each of the 11 original data sites, as well as the first two authors' institutions, approved this study.

\section{Measures}

Demographic information-All studies collected sex, racial/ethnic information, and education status. Education was chosen as a proxy of SES in part because data were collected at distinct geographic locations in the United States with different average household incomes and price indices and because education has been found to be a better predictor of health-related outcomes than income (Ross \& Mirowsky, 1999). Education was coded as less than 12 years of education, 12 years or the equivalent (high school or general equivalency diploma), 13-15 years, 16 years (a 4-year college degree), and postgraduate education. For the purposes of secondary comparisons to epidemiological data, the highest two categories-college degree and postgraduate education-were combined to allow comparison to categories in publicly available survey data.

BMI-In each study, participants' height was measured with a stadiometer, and weight was measured with a balance beam scale by study personnel, from which BMI $\left(\mathrm{kg} / \mathrm{m}^{2}\right)$ was calculated.

Eating Disorder Examination (EDE)—Treatment studies employed this semistructured investigator-based interview to assess BED and its features, including number of objective binge episodes (OBEs; eating unusually large quantities of food while experiencing loss of control, which corresponds to the Diagnostic and Statistical Manual of Mental Disorders definition of binge eating; American Psychiatric Association, 1994) and subjective binge episodes (SBEs) over the past 28 days (Fairburn \& Cooper, 1993). The EDE yields four subscale scores-Restraint, Eating Concern, Weight Concern, and Shape Concern-as well as a global score, which is an average of all four subscales. Respondents indicate whether the item has been true over the previous 28 days (yes or no) and, if so, on how many days or how many times it has occurred. A global score is also reported, following the scoring suggested by Fairburn \& Beglin (1994). Subscale scores exceeding 4.0 indicate clinical concern. The EDE has shown acceptable psychometric properties across eating disorders (Fairburn \& Cooper, 1993) and performs well with racial and ethnic minority groups (Grilo, Lozano, \& Elder, 2005; Grilo, Masheb, Lozano-Blanco, \& Barry, 2004). Two of the trials (Gorin et al., 2003; Kristeller, 2007) used the questionnaire version of the EDE (EDE-Q) rather than the interview (Fairburn \& Beglin, 1994) and made BED diagnoses using the Structured Clinical Interview for DSM-IV Axis I Disorders (First, Spitzer, Gibbon, \& Williams, 1996). Studies have documented good agreement between the EDE-Q and the EDE on frequency of OBEs and subscale scores among patients with BED (Grilo, Masheb, \& Wilson, 2001).

Collaborative psychiatric epidemiology surveys-To examine differences between individuals with BED in the CT-BED database and community-based samples regarding age, sex, education, and BMI, we used three publicly available databases from well-known national survey studies (Heeringa et al., 2004): the National Comorbidity SurveyReplication, the National Survey of American Life, and the National Latino and Asian American Study, which are included in the Collaborative Psychiatric Epidemiology Surveys (CPES). These studies collected nationally representative data $(N>15,000)$ via phone interview on mental disorders in the general population, with special emphasis on minority groups in the latter two surveys (Heeringa et al., 2004). Interviews covered multiple mental 
health issues, including eating disorder symptoms, as well as sociocultural factors such as education and acculturation. We used data from the 64 participants in the CPES from the racial/ethnic groups examined in this study (25 non-Latino Caucasian, 22 African American/ Caribbean Black, and 17 Hispanic) who endorsed binge eating and associated distress and impairment at the full-criteria, diagnostic level within the past 30 days. The prevalence of BED was $.45 \%$. Although the prevalence is seemingly low, this should be tempered by the fact that we examined current (i.e., 30-day) diagnoses. It is important to note that our lifetime prevalence estimate for BED was well within the range of recent epidemiological and community studies (Hudson et al., 2007; Marques et al., 2011; Stice, Marti, Shaw, \& Jaconis, 2009). Moreover, Marques et al. (2011) previously reported the prevalence of BED using the CPES data set. Although they used Bayesian estimation to model prevalence rates, due to small sample sizes, it should be noted that our results are highly consistent.

\section{Statistical Analyses}

The analyses examined baseline measures from the studies in the database. Analyses focused on racial/ethnic differences in baseline BMI and EDE variables (global and subscale scores as well as OBEs and SBEs), adjusting for age and gender. To examine whether racial/ ethnic differences in EDE, OBE, and SBE were mediated by BMI and education, we created two models (Model 1 adjusting for race/ethnicity only vs. Model 2 adjusting for race/ ethnicity, BMI, and education) and described changes in the estimated race/ethnicity effects between the two models. To determine whether the association of education with EDE, OBE, and SBE would vary by race/ethnicity, we estimated the association of education with each outcome variable separately for each racial/ethnic group.

The observations (respondents) were not independent, due to potential similarity among respondents within study sites. To account for this, we adjusted confidence intervals (Wolter, 1985) and conducted statistical tests using mixed models. In the mixed models, the data set was treated as if it were a multisite clinical trial (Brown \& Prescott, 1999), with a random intercept for study site. Multiple imputation was used to handle missing data (Allison, 2001). Statistical tests were done with measures on their original scale, except that OBE was log transformed prior to analysis due to a nonnormal residual distribution, and SBE was converted to a set of binary variables due to extreme skewness of the distribution. All reported results were significant at $p<.05$. All outcomes were modeled as continuous (using PROC MIXED in SAS 9.1), except that the two SBE indicators were modeled as binary via logistic regression (PROC NLMIXED in SAS).

\section{Results}

\section{Racial/Ethnic Group Differences in Demographics and Symptoms}

Table 1 shows the number of participants in the study sample by race/ethnicity, study site, education, and gender. Hispanic participants were significantly more likely than Caucasians to have less than a high school education $(7.8 \%$ vs. $0.8 \% ; p<.005)$. Caucasians in the sample were significantly more likely to be male than were African Americans $(16.0 \%$ vs. $9.8 \% ; p<.05)$. Age did not vary by race/ethnicity $(p>.38)$; the mean age in the sample was 47.0 years $(S D=10.7)$ for Caucasians, 45.1 years $(S D=11.4)$ for African Americans, and 42.7 years $(S D=10.1)$ for Hispanics.

Table 2 displays BED symptoms and BMI by racial/ethnic group. Analyses indicated that African Americans in the sample had significantly greater BMI than Caucasians $(p<.001)$. Hispanic participants had significantly higher Global, Eating Concern, and Shape Concern scores on the EDE compared with Caucasians $(p s<.05)$. Hispanic participants also had significantly greater Eating Concern scores compared with African Americans $(p<.05)$. 
African Americans had significantly higher Restraint scores on the EDE than Caucasians ( $p$ $<.01)$. There were no racial/ethnic differences for frequency of binge eating episodes (objective or subjective), as indicated by $19.25,19.16$, and 18.07 objective binge eating episodes occurring over the previous 28 days by Caucasian, African American, and Hispanic participants, respectively. Similarly, $18 \%$ of Caucasians, $13 \%$ of African Americans, and $19 \%$ of Hispanics reported more than 16 subjective binge eating episodes in the previous month.

\section{Potential Mediators of Racial/Ethnic Group Differences in BED Symptoms}

To examine the possibility that racial/ethnic differences in EDE described above might be partially explained by differences in BMI and education, we constructed two models for the EDE Global scale and each subscale (see Table 3). To the extent that the parameter estimates $(\beta)$ for race/ethnicity decrease between Models 1 and 2, this finding would indicate that the differences are partly explained by BMI and/or education. The results suggest that BMI and education explained little of the difference between Caucasians and Hispanics for EDE Global, Eating Concern, and Shape Concern, given that parameter estimates for race/ethnicity changed less than $1 \%$ in Model 1 versus Model 2. However, the difference between African Americans and Caucasians on EDE Restraint actually increased by about $23 \%$ when adjusting for BMI and education. Follow-up analyses showed that this increase was likely due to an interaction between BMI and race/ethnicity with respect to Restraint (see Figure 1). Analyses indicated decreased Restraint among Caucasians with above the sample mean BMI but increased Restraint among African Americans with above sample mean BMI. Model 1 mixes participants with above versus below mean BMI, diluting the estimated effect of Restraint scores observable among only African Americans with higher BMI. However, Model 2 holds BMI constant, and the estimated racial/ethnic difference in Restraint is therefore greater.

The effect of education was estimated separately for each racial/ethnic group, for each EDE subscale. None of the differences between categories of education was statistically significant $(p \mathrm{~s}>.10)$, and $r^{2}$ values representing the size of the education effect were uniformly small $\left(r^{2}<.005\right)$, indicating that education explained no more than half of $1 \%$ of the variance in severity, regardless of race or ethnicity.

\section{Generalizability of BED Clinical Trial Data to the General Population}

To examine the generalizability of this national sample of clinical trial data, we compared data from CT-BED to publicly available data from the CPES, on variables that permitted comparison: age, sex, BMI, and level of education. Comparisons were first conducted for each racial/ethnic group separately. Two-group analysis of variance was used to compare age and BMI within each racial/ethnic group, and Pearson's chi-square test of general association was used to assess sex and level of education. As shown in Table 4, significant differences were found between the clinical samples and the nonclinical samples for BMI and years of education. As expected, the clinical trial sample had higher mean BMIs than the community samples (the difference for Hispanics was only at a nonsignificant trend level). Years of education differentiated the groups. Among African Americans with BED in clinical trials, for example, only $0.8 \%$ had less than a high school education (12 years). However, among African Americans in the community with BED, 24.0\% had less than a high school education. As a further example, among Hispanics with BED in clinical trials, $39.7 \%$ had at least a college education; however, among Hispanics in the community with BED, only $5.9 \%$ of the sample had a college education. Across all the clinical trial data in CT-BED, only 24 African American and Latino/Hispanic individuals with no college education were included in the studies. 
No significant differences were found within any racial/ethnic group for age or sex. However, given the underpowered nature of these analyses, comparisons were conducted with the entire sample as well. In comparisons of all participants (Caucasian, African American, and Hispanics) in CT-BED to all those with BED from the same groups in CPES (also combined), the differences in mean age achieved statistical significance. For the clinical sample, mean age was 46.29 years $(S D=10.90)$, whereas for the nonclinical sample, mean age was $42.30(S D=12.84), F(1,1450)=8.07, p=.005$. However, differences in representation of male subjects in each sample were still nonsignificant (Pearson $\chi^{2}=0.161$, $p=.398)$.

\section{Discussion}

This study revealed racial/ethnic differences in demographic variables, mean BMI, and features of eating disorder psychopathology among Caucasian, African American, and Hispanic participants who were enrolled in treatment trials for BED. Demographically, no age differences were found, but fewer African American men than Caucasian men participated in the clinical trials, and Hispanic participants were less educated than the Caucasian sample. Interestingly, Hispanic individuals evidenced greater symptoms of eating pathology than both Caucasian and African American participants, indicating that they reported the strongest distress about body shape and weight. African Americans showed higher restraint scores than Caucasians (but not Hispanics), indicating more efforts to control food intake. Although racial/ethnic group differences in severity of eating disorder features were observed, no group differences in the reported frequency of either objective or subjective binge eating episodes were found.

Although some research suggests that Hispanics in nonclinical samples show more positive attitudes toward weight gain (Cachelin, Veisel, Barzegarnazari, \& Striegel-Moore, 2000; Massara, 1989), other studies have found that body dissatisfaction is high among Hispanics (Chamorro \& Flores-Ortiz, 2000) or may fall between Caucasian and African American groups (Vander Wal \& Thomas, 2004). The current study indicates that treatment-seeking Hispanic adults may present with significantly greater body shape and eating concerns relative to other racial/ethnic groups, suggesting that taking into account culturally relevant variables may be important when treating Hispanic women with BED.

Although greater body satisfaction and more weight tolerant attitudes observed among African American women in the general population may be a protective factor against the development of some eating disorders, researchers speculate that these same attitudes may increase risk for binge eating and obesity due to the absence of motivation to avoid weight gain (Fitzgibbon et al., 1998). Data from treatment-seeking samples with BED, including our own, are somewhat inconsistent on this point. In a previous study of racial/ethnic differences among treatment-seeking women with BED, Black women showed significantly higher BMI scores than White women but lower levels of weight concern (Grilo, Lozano, \& Masheb, 2005). In contrast, another study of treatment-seeking African American women with eating disorders also observed higher average BMI, but also higher fear of weight gain than other racial and ethnic groups (Fernandes, Crow, Thuras, \& Peterson, 2010). In the present study, African American treatment-seeking women showed comparable levels of body shape, eating, and weight concern to Caucasian women, despite differences in BMI. However, our data also indicated higher dietary restraint scores in the African American participants relative to the Caucasian participants, suggesting that African Americans with BED were highly motivated to reduce their weight and more likely to engage in dietary restraint. These observed differences were particularly notable among the subset of women with extremely high BMI scores. It would have been of interest to examine the extent to which physical activity may have influenced these findings, which unfortunately was not 
available in the data set. In summary, our own data suggest that treatment-seeking African American women with BED and obesity do not show the more weight-tolerant attitudes observed in some studies of the general population.

Although race/ethnicity was associated with features of eating disorder pathology, no differences were found in either OBEs or SBEs across the three groups. This may have been due to the fact that in order to participate in the RCT, participants had to meet the diagnostic criteria for BED, which includes binge eating at least twice weekly on average over the previous 6 months, which compressed the range at the outset. The frequency of binge eating episodes contrasts to levels of distress across the groups, wherein Hispanic participants, on average, had higher levels of body shape and eating concerns, and African Americans had higher restraint scores, relative to the Caucasian participants. These findings would suggest that interventions targeting specific behavioral components of the disorder should be similar across racial/ethnic groups, but strategies that address sources of distress might best be tailored in order to be most effective.

Findings from the present study also revealed that differences on EDE subscales among the racial/ethnic groups were not accounted for by SES and BMI. Epidemiological research suggests that the relationships among race, ethnicity, SES, BMI, and health behaviors include complex interactions and must be considered together (Farmer \& Ferraro, 2005). Epidemiological and community studies have tended to focus on the risk conferred by lower SES, finding that low SES is associated with higher risk of BED across racial and ethnic groups (Alegria et al., 2007; Reagan \& Hersch, 2005; Striegel-Moore, Wilfley, Pike, Dohm, $\&$ Fairburn, 2000). Many studies of health issues note that observed differences between racially or ethnically defined groups are better attributed to differences in SES (Wilfley et al., 2001). Our data, however, indicated that the observed racial/ethnic differences in a treatment-seeking BED population persist or increase after controlling for BMI and SES. It is possible that additional variables, such as depression, economic hardship, or stress, may help explain differences in eating disorder presentation better than education level. Alternatively, differences in cultural value systems shared by racial/ethnic groups may account for these findings.

Notably, some of the observed differences may be specific to the population that seeks treatment for BED in treatment trials. It is possible that the higher levels of distress about eating disorder features and higher BMI observed in this study among Hispanics and African Americans, respectively, do not generalize beyond this population. Possibly, members of racial and ethnic minority groups must have higher levels of eating disorder symptoms as a threshold for treatment seeking, whereas those in the community with BED have comparable rates of symptomatology but are less likely to seek treatment (Pike et al., 2001).

Findings from this study also raise significant concerns about the generalizability of clinical trial data to the general population with BED. As expected from previous studies of treatment-seeking biases (Fairburn, Welch, Norman, O'Connor, \& Doll, 1996), individuals who sought treatment had higher BMIs, older age, and higher levels of education. Although these findings are not unique, they have important implications for claims regarding the treatment efficacy of treatments for BED. Our analyses suggest that across 11 RCTs for $\mathrm{BED}$, comprising most of the known information regarding treatment efficacy, very few individuals from African American and Hispanic backgrounds without some college education were included. However, epidemiological data suggest that the majority of those with BED in the community have a high school education or less. Although there are many known obstacles to recruitment to clinical trials from minority racial/ethnic groups and groups with lower SES (U.S. Department of Health and Human Services, 2001), and investigators typically make strenuous efforts to increase diversity in their studies, it appears 
that little is yet known about the clinical presentation or treatment efficacy for individuals with BED from minority racial and ethnic backgrounds with lower levels of educational attainment.

This study has several implications for the delivery of effective treatments for BED for racial/ethnic minorities. First, our data, in accordance with prior research, suggest that treatment-seeking individuals from minority groups show substantial distress and suffering associated with their eating disorder and with obesity, and on some indicators appear to show higher severity than Caucasians who seek treatment in RCTs. Second, our data suggest that very few individuals from racial or ethnic minority backgrounds-particularly few individuals with lower levels of educational attainment-have sought treatment for BED in RCTs. Potential reasons for this underrepresentation include possible cultural differences in attitudes toward treatment studies, concerns among some groups regarding immigration status, or different levels of educational attainment among those in proximity to the location where treatment studies are conducted. However, our results also indicate that known treatments for BED have not yet been tested with adequate, representative samples to demonstrated efficacy with this group.

In order to engage minorities with lower levels of educational attainment in treatment of any kind, including in treatment trials, it may be necessary to conduct treatment and research in different settings than has previously been the case, such as community hospital weight management programs, or even less clinical and more community-based settings (e.g., YMCA, church groups). Moreover, the content of treatment programs and treatment research may need to be presented differently from how it has been. Although this study did not focus on recruitment methods, it is possible that treatment should not be presented as targeting an eating disorder, or binge eating, but rather requires a more general focus. More data documenting the process of and obstacles to engagement in treatment among those with lower levels of educational attainment are needed. In summary, findings from this study beg the question of how we can take our effective treatments to those where the need is great but the utilization is low.

Although this study is limited by the relatively small size of African American and Hispanic samples, and the limitations of measures assessing eating disorder behaviors, it represents one of the first studies to examine racial/ethnic differences in symptomatology among individuals with BED in clinical trials. Furthermore, nearly all the analyses were amply powered to detect small to medium effect sizes (Cohen, 1988). A few group comparisonsparticularly those comparing the Hispanic sample to other racial/ethnic groups-were limited in power to detect small effects, and nonsignificant findings regarding Hispanics should be considered with this limitation in mind. Moreover, there are limitations to combining separate RCTs into a single data set, including differences in geographical setting, types of treatment provided, and racial/ethnic minority representation that differed across studies. Although we attempted to include data from all existing RCTs that met the inclusion criteria, two studies could not be included, and thus there may have been some selection bias in the studies examined. In addition, selection bias operates whenever data from RCTs are examined, given that the sample that participates in an RCT may be different from the general population due to a variety of factors (e.g., the nature of the degree of involvement to participate in an RCT, lengthy assessment procedures, agreement to the possibility of randomization to the control group). Bias may also occur in that individuals who participate in an RCT might not be representative of individuals who spontaneously present for routine treatment to their personal provider. The comparison of the RCT data to the epidemiologic data is also limited by the differences in sample size, recruitment means, and documented differences between treatment-seeking and nontreatment-seeking samples (Wilfley et al., 2001). 
Despite the limitations, the study was able to identify multiple significant results concerning racial/ethnic group differences on a variety of eating disorder features, BMI, and demographic variables, which contribute substantially to our knowledge of treatmentseeking samples. The issues related to generalizability suggest that additional studies that include minorities with lower levels of educational attainment are critical. Research exploring other social and cultural factors beyond SES that may contribute to racial/ethnic differences is needed, as are studies that examine the role of race and ethnicity in relation to treatment outcome.

\section{Acknowledgments}

This research was supported by National Institutes of Health Grant R03MH083987 to Debra L. Franko and Heather Thompson-Brenner (principal investigators).

\section{References}

American Psychiatric Association. Diagnostic and statistical manual of mental disorders. 4. Washington, DC: Author; 1994.

Alegria M, Woo M, Cao Z, Torres M, Meng XL, Striegel-Moore RH. Prevalence and correlates of eating disorders in Latinos in the United States. International Journal of Eating Disorders. 2007; 40(Suppl):S15-S21.10.1002/eat.20406 [PubMed: 17584870]

Allison, PD. Missing data. Thousand Oaks, CA: Sage; 2001.

Brown, H.; Prescott, R. Applied mixed models in medicine. New York, NY: Wiley; 1999.

Cachelin FM, Veisel C, Barzegarnazari E, Striegel-Moore RH. Disordered eating, acculturation, and treatment-seeking in a community sample of Hispanic, Asian, Black, and White women. Psychology of Women Quarterly. 2000; 24:244-253.10.1111/j.1471-6402.2000.tb00206.x

Chamorro R, Flores-Ortiz Y. Acculturation and disordered eating patterns among Mexican American women. International Journal of Eating Disorders. 2000; 28:125-129.10.1002/ (SICI)1098-108X(200007)28:1<125::AID-EAT16>3.0.CO;2-9 [PubMed: 10800023]

Cohen, J. Statistical power analysis for the behavioral sciences. 2. Hillside, NJ: Erlbaum; 1988.

Devlin MJ, Goldfein JA, Petkova E, Jiang H, Raizman PS, Wolk S, Walsh BT. Cognitive behavioral therapy and fluoxetine as adjuncts to group behavioral therapy for binge eating disorder. Obesity Research. 2005; 13:1077-1088.10.1038/oby.2005.126 [PubMed: 15976151]

Dickerson JF, Debar L, Perrin NA, Lynch F, Wilson GT, Rosselli F, Striegel-Moore RH. Healthservice use in women with binge eating disorders. International Journal of Eating Disorders. 2011; 44:524-530.10.1002/eat.20842 [PubMed: 21823138]

Fairburn CG, Beglin SJ. Assessment of eating disorders: Interview or self-report questionnaire? International Journal of Eating Disorders. 1994; 16:363370.10.1002/1098-108X(199412)16:4<363::AID-EAT2260160405>3.0.CO;2-\# [PubMed: 7866415]

Fairburn, CG.; Cooper, Z. The Eating Disorder Examination. In: Fairburn, CG.; Wilson, GT., editors. Binge eating: Nature, assessment, and treatment. 12. New York, NY: Guilford Press; 1993. p. 317-360.

Fairburn CG, Welch SL, Norman PA, O'Connor ME, Doll HA. Bias and bulimia nervosa: How typical are clinic cases? American Journal of Psychiatry. 1996; 153:386-391. [PubMed: 8610827]

Farmer MM, Ferraro KF. Are racial disparities in health conditional on socioeconomic status? Social Science Medicine. 2005; 60:191-204.10.1016/j.socscimed.2004.04.026 [PubMed: 15482878]

Fernandes NH, Crow SJ, Thuras P, Peterson CB. Characteristics of Black treatment seekers for eating disorders. International Journal of Eating Disorders. 2010; 43:282-285.10.1002/eat.20684 [PubMed: 19343798]

First, MB.; Spitzer, RL.; Gibbon, M.; Williams, JBW. Structured Clinical Interview for DSM-IV Axis I Disorders, Patient Edition (SCID-P. New York, NY: New York State Psychiatric Institute, Biometrics Research; 1996. 
Fitzgibbon ML, Spring B, Avellone ME, Blackman LR, Pingitore R, Stolley MR. Correlates of binge eating in Hispanic, Black, and White women. International Journal of Eating Disorders. 1998; 24:43-52.10.1002/(SICI)1098-108X(199807)24:1<43::AID-EAT4>3.0.CO;2-0 [PubMed: 9589310]

Flegal KM, Carroll MD, Ogden CL, Curtin LR. Prevalence and trends in obesity among US adults, 1999-2008. Journal of the American Medical Association. 2010; 303:235-241.10.1001/jama. 2009.2014 [PubMed: 20071471]

Gorin AA, Le Grange D, Stone AA. Effectiveness of spouse involvement in cognitive behavioral therapy for binge eating disorder. International Journal of Eating Disorders. 2003; 33:421433.10.1002/eat.10152 [PubMed: 12658672]

Grilo, CM. Binge eating disorder. In: Fairburn, CG.; Brownell, KD., editors. Eating disorders and obesity: A comprehensive handbook. 2. New York, NY: Guilford Press; 2003. p. 178-182.

Grilo CM, Lozano C, Elder KA. Inter-rater and test-retest reliability of the Spanish version of the Eating Disorder Examination Interview: Clinical and research implications. Journal of Psychiatric Practice. 2005; 11:231-240. 00131746-200507000-00003. [PubMed: 16041233]

Grilo CM, Lozano C, Masheb RM. Ethnicity and sampling bias in binge eating disorder: Black women who seek treatment have different characteristics than those who do not. International Journal of Eating Disorders. 2005; 38:257-262.10.1002/eat.20183 [PubMed: 16211631]

Grilo CM, Masheb RM. A randomized controlled comparison of guided self-help cognitive behavioral therapy and behavioral weight loss for binge eating disorder. Behaviour Research and Therapy. 2005; 43:1509-1525.10.1016/j.brat.2004.11.010 [PubMed: 16159592]

Grilo CM, Masheb RM, Lozano-Blanco C, Barry DT. Reliability of the Eating Disorder Examination in patients with binge eating disorder. International Journal of Eating Disorders. 2004; 35:8085.10.1002/eat.10238 [PubMed: 14705160]

Grilo CM, Masheb RM, Salant SL. Cognitive behavioral therapy guided self-help and orlistat for the treatment of binge eating disorder: A randomized, double-blind, placebo-controlled trial. Biological Psychiatry. 2005; 57:1193-1201.10.1016/j.biopsych.2005.03.001 [PubMed: 15866560]

Grilo CM, Masheb RM, Wilson GT. Subtyping binge eating disorder. Journal of Consulting and Clinical Psychology. 2001; 69:1066-1072.10.1037/0022-006X.69.6.1066 [PubMed: 11777111]

Grilo CM, Masheb RM, Wilson GT. Efficacy of cognitive behavioral therapy and fluoxetine for the treatment of binge eating disorder: A randomized double-blind placebo-controlled comparison. Biological Psychiatry. 2005; 57:301-309.10.1016/j.biopsych.2004.11.002 [PubMed: 15691532]

Heeringa SG, Wagner J, Torres M, Duan N, Adams T, Berglund P. Sample designs and sampling methods for the Collaborative Psychiatric Epidemiology Studies (CPES). International Journal of Methods in Psychiatric Research. 2004; 13:221-240.10.1002/mpr.179 [PubMed: 15719530]

Hudson JI, Hiripi E, Pope HG Jr, Kessler RC. The prevalence and correlates of eating disorders in the National Comorbidity Survey Replication. Biological Psychiatry. 2007; 61:348-358.10.1016/ j.biopsych.2006.03.040 [PubMed: 16815322]

Kristeller, JL. Mindfulness-based eating awareness therapy (MB-EAT). Paper presented at the International Conference on Eating Disorders; Baltimore, MD. 2007 Apr.

Latner JD, Wetzler S, Goodman ER, Glinski J. Gastric bypass in a low-income, inner-city population: Eating disturbances and weight loss. Obesity Research. 2004; 12:956-961.10.1038/oby.2004.117 [PubMed: 15229335]

Marcus MD, Bromberger JT, Wei H-L, Brown C, Kravitz HM. Prevalence and selected correlates of eating disorder symptoms among a multiethnic community sample of midlife women. Annals of Behavioral Medicine. 2007; 33:269-277.10.1007/BF02879909 [PubMed: 17600454]

Marcus MD, Wildes JE. Obesity: Is it a mental disorder? International Journal of Eating Disorders. 2009; 42:739-753.10.1002/eat.20725 [PubMed: 19610015]

Marques L, Alegria M, Becker AE, Chen C, Fang A, Chosak A, Diniz JB. Comparative prevalence, correlates of impairment, and service utilization for eating disorders across US ethnic groups: Implications for reducing ethnic disparities in health care access for eating disorders. International Journal of Eating Disorders. 2011; 44:412-420.10.1002/eat.20787 [PubMed: 20665700]

Massara, EB. !Que Gordita! A study of weight among women in a Puerto Rican community. New York, NY: AMS Press; 1989. 
Peterson CB, Mitchell JE, Crow SJ, Crosby RD, Wonderlich SA. The efficacy of self-help group treatment and therapist-led group treatment for binge eating disorder. American Journal of Psychiatry. 2009; 166:1347-1354.10.1176/appi.ajp.2009.09030345 [PubMed: 19884223]

Pike KM, Dohm F-A, Striegel-Moore RH, Wilfley DE, Fairburn CG. A comparison of Black and White women with binge eating disorder. American Journal of Psychiatry. 2001; 158:14551460.10.1176/appi.ajp.158.9.1455 [PubMed: 11532731]

Reagan P, Hersch J. Influence of race, gender, and socioeconomic status on binge eating frequency in a population-based sample. International Journal of Eating Disorders. 2005; 38:252-256.10.1002/ eat.20177 [PubMed: 16211628]

Ross CE, Mirowsky J. Refining the association between education and health: The effects of quantity, credential, and selectivity. Demography. 1999; 36:445-460. [PubMed: 10604074]

Safer DL, Robinson AH, Jo B. Outcome from a randomized controlled trial of group therapy for binge eating disorder: Comparing dialectical behavior therapy adapted for binge eating to an active comparison group therapy. Behavior Therapy. 2010; 41:106-120.10.1016/j.beth.2009.01.006 [PubMed: 20171332]

Shapiro JR, Reba-Harrelson L, Dymek-Valentine M, Woolson SL, Hamer RM, Bulik CM. Feasibility and acceptability of CD-ROM-based cognitive-behavioural treatment for binge-eating disorder. European Eating Disorders Review. 2007; 15:175-184.10.1002/erv.787 [PubMed: 17676687]

Stice E, Marti CN, Shaw H, Jaconis M. An 8-year longitudinal study of the natural history of threshold, subthreshold, and partial eating disorders from a community sample of adolescents. Journal of Abnormal Psychology. 2009; 118:587-597.10.1037/a0016481 [PubMed: 19685955]

Striegel-Moore RH, Fairburn CG, Wilfley DE, Pike KM, Dohm F-A, Kraemer HC. Toward an understanding of risk factors for binge-eating disorder in Black and White women: A communitybased case-control study. Psychological Medicine. 2005; 35:907-917.10.1017/ S0033291704003435 [PubMed: 15997611]

Striegel-Moore RH, Franko DL. Should binge eating disorder be included in the DSM-V? A critical review of the state of the evidence. Annual Review of Clinical Psychology. 2008; 4:305324.10.1146/annurev.clinpsy.4.022007.141149

Striegel-Moore RH, Wilfley DE, Pike KM, Dohm FA, Fairburn CG. Recurrent binge eating in Black American women. Archives of Family Medicine. 2000; 9:83-87. [PubMed: 10664648]

U.S. Department of Health and Human Services. Mental health: Culture, race, and ethnicity: A supplement to Mental Health: A Report of the Surgeon General. Rockville, MD: U.S. Department of Health and Human Services, Substance Abuse and Mental Health Services Administration; 2001.

Vander Wal JS, Thomas N. Predictors of body image dissatisfaction and disturbed eating attitudes and behaviors in African American and Hispanic girls. Eating Behaviors. 2004; 5:291-301.10.1016/ j.eatbeh.2004.04.001 [PubMed: 15488444]

Wilfley DE, Pike KM, Dohm F-A, Striegel-Moore RH, Fairburn CG. Bias in binge eating disorder: How representative are recruited clinic samples? Journal of Consulting and Clinical Psychology. 2001; 69:383-388.10.1037/0022-006X.69.3.383 [PubMed: 11495168]

Wilfley DE, Welch RR, Stein RI, Spurrell EB, Cohen LR, Saelens BE, Matt GE. A randomized comparison of group cognitive-behavioral therapy and group interpersonal psychotherapy for the treatment of overweight individuals with binge-eating disorder. Archives of General Psychiatry. 2002; 59:713-721.10.1001/archpsyc.59.8.713 [PubMed: 12150647]

Wilson GT, Wilfley DE, Agras WS, Bryson SW. Psychological treatments of binge eating disorder. Archives of General Psychiatry. 2010; 67:94-101.10.1001/archgenpsychiatry.2009.170 [PubMed: 20048227]

Wolter, KM. Introduction to variance estimation. New York, NY: Springer-Verlag; 1985.

Wonderlich SA, Gordon KH, Mitchell JE, Crosby RD, Engel SG. The validity and clinical utility of binge eating disorder. International Journal of Eating Disorders. 2009; 42:687-705.10.1002/eat. 20719 [PubMed: 19621466] 


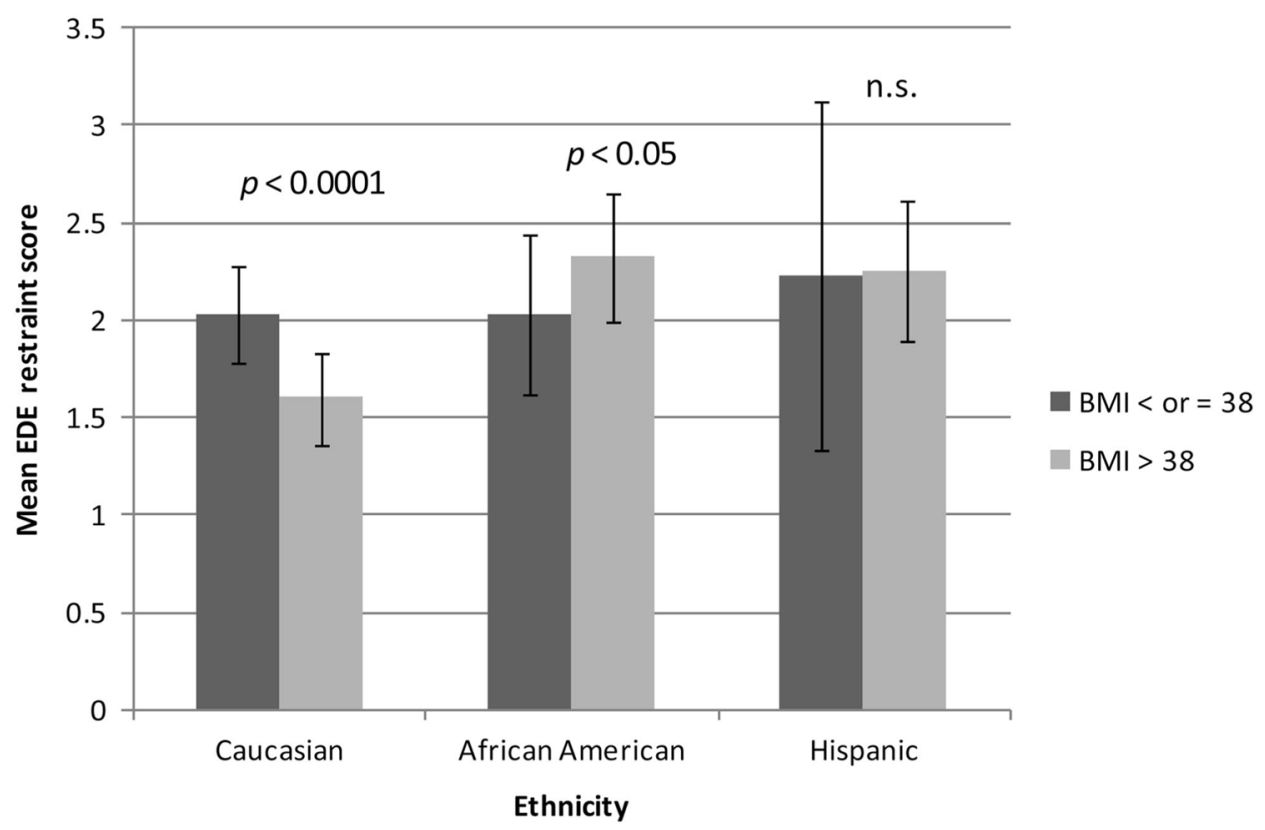

Figure 1.

Mean Eating Disorder Examination (EDE) Restraint score (95\% confidence interval) by race/ethnicity for participants above versus at or below the sample mean body mass index (BMI) of 38 . 


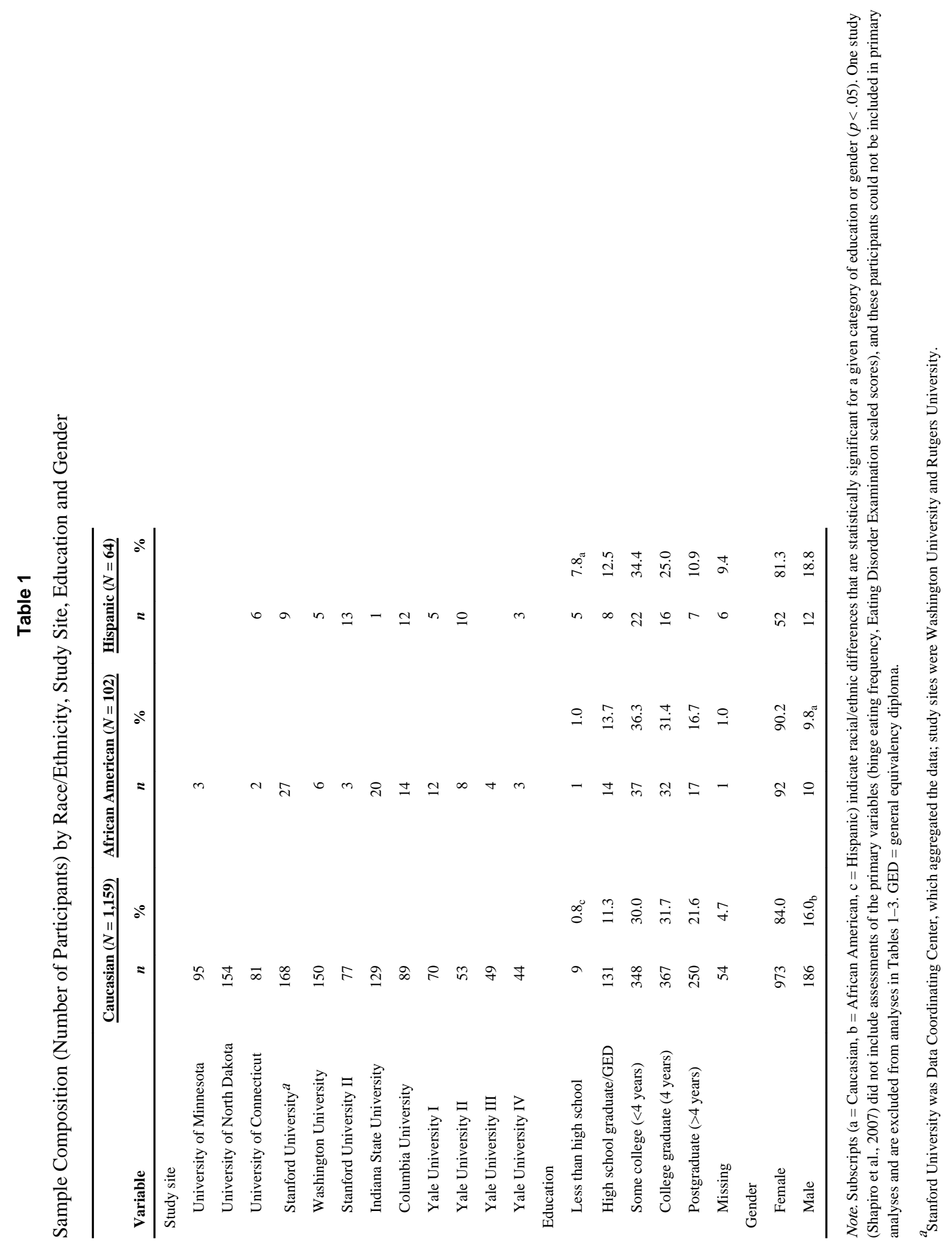




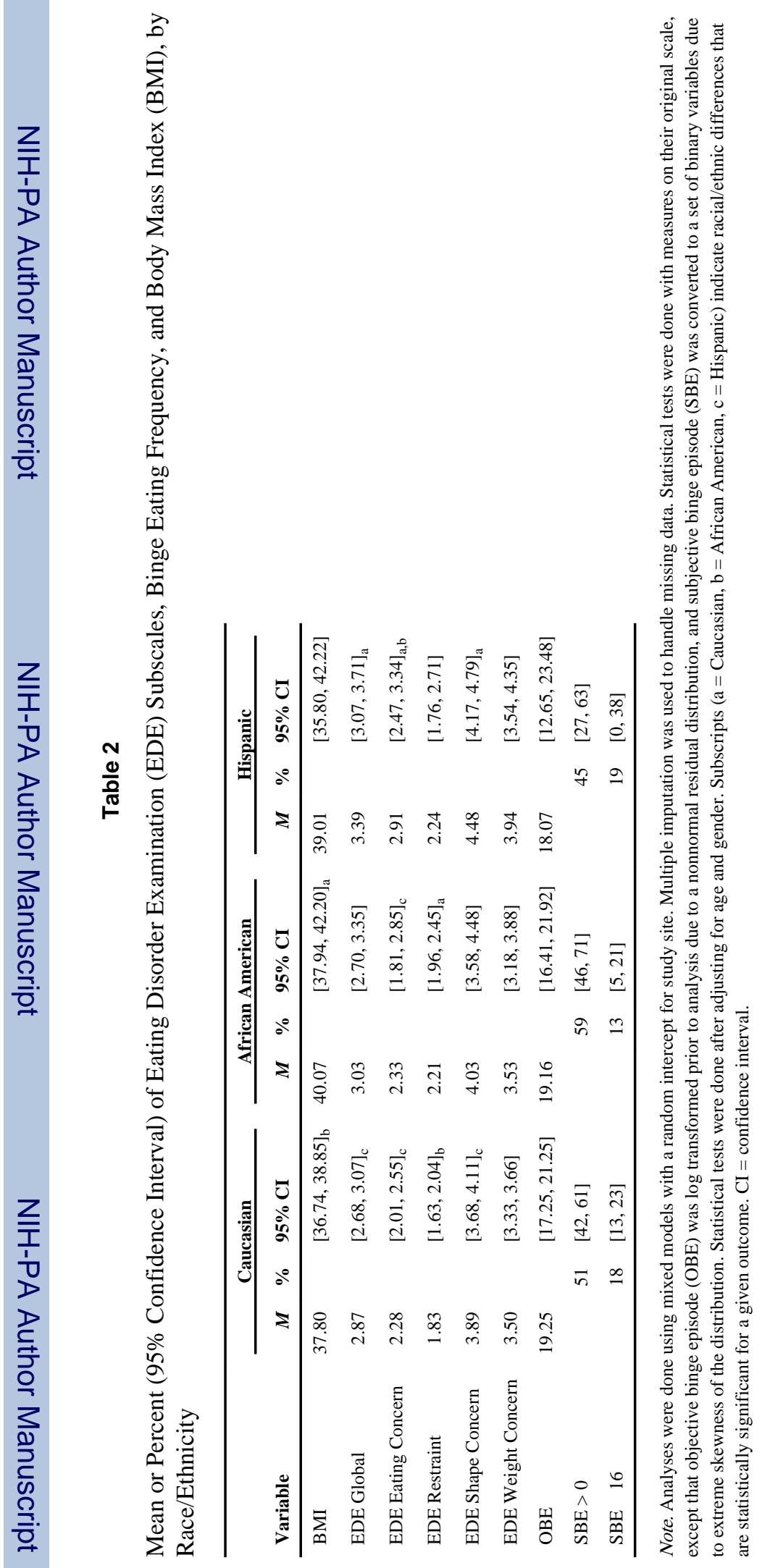




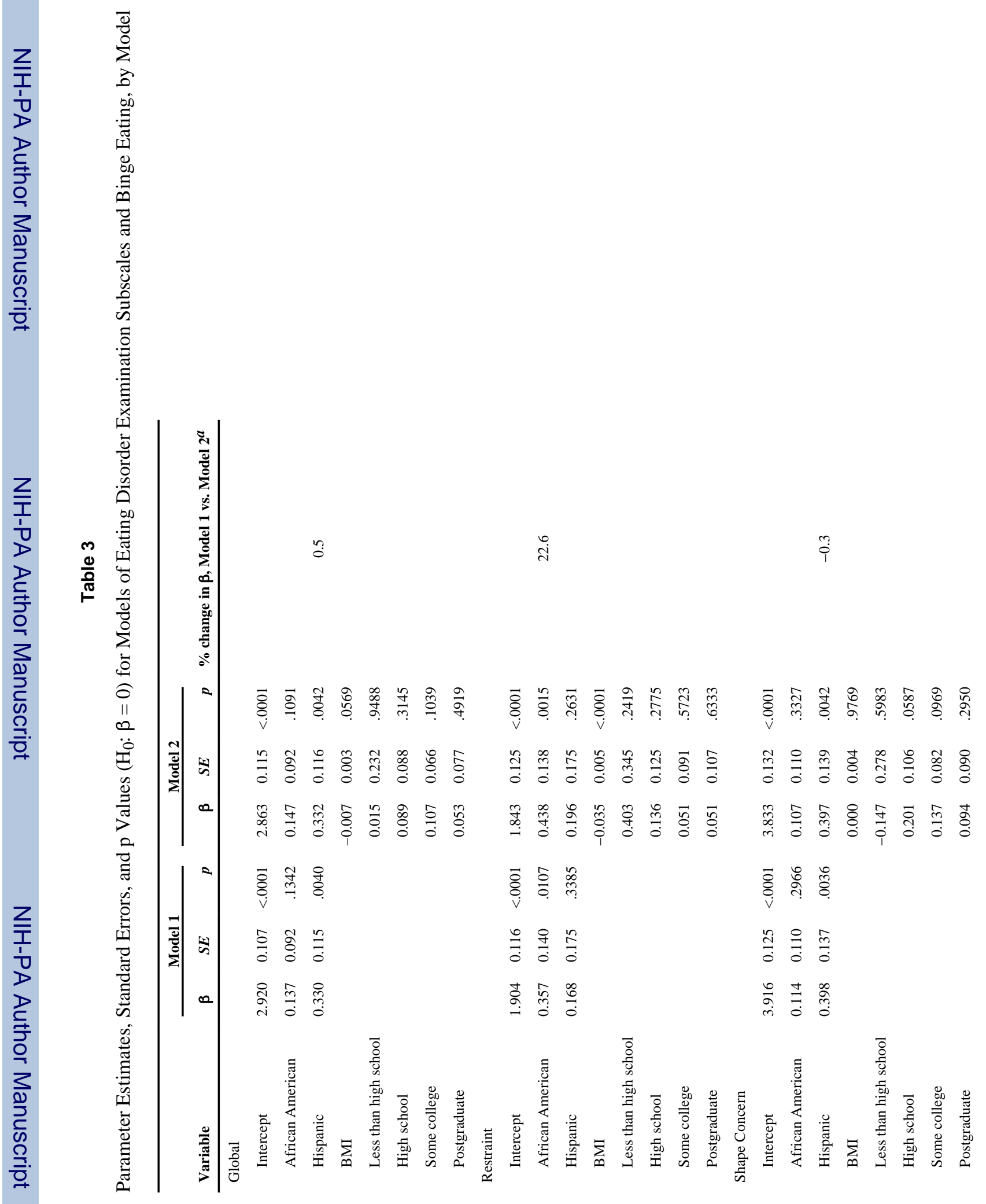




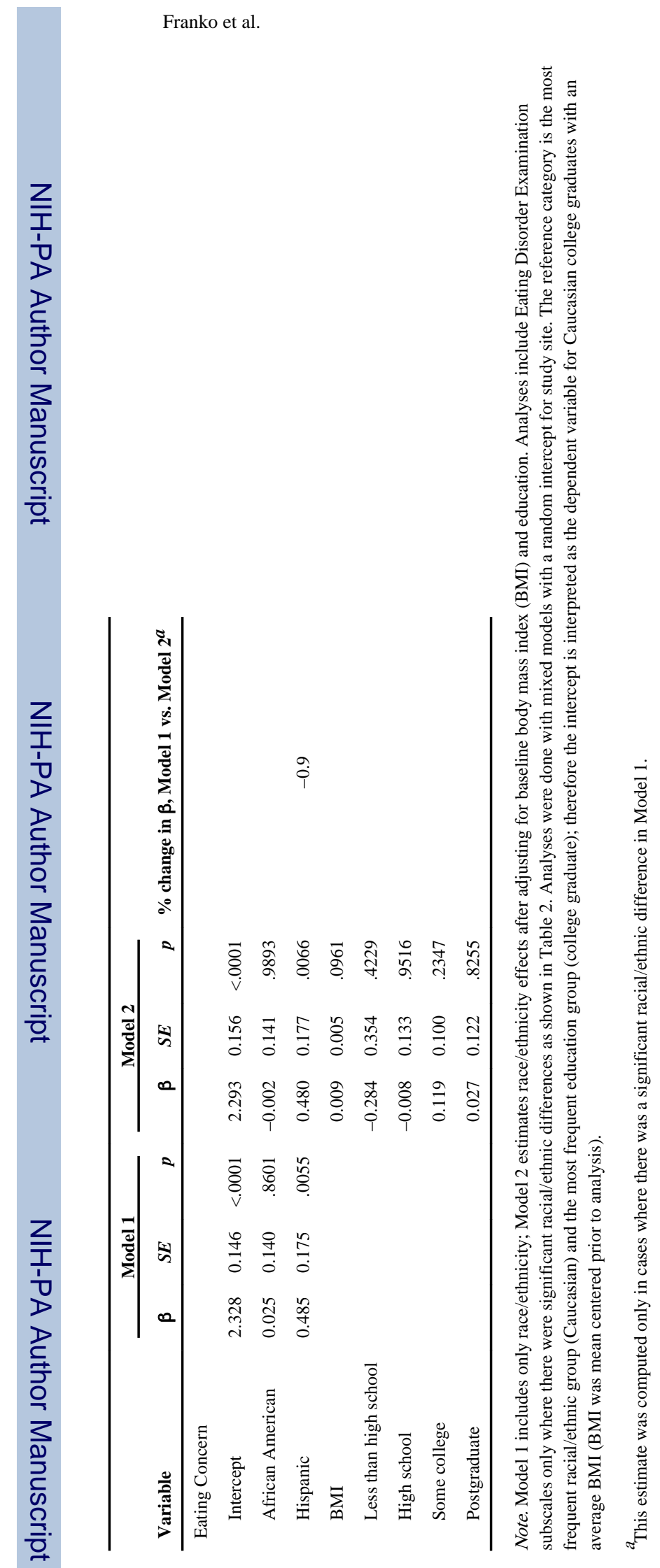

J Consult Clin Psychol. Author manuscript; available in PMC 2013 May 31. 


$$
\text { 植 }
$$

